\title{
Evaluación del contenido de cadmio en suelos destinados al cultivo de cacao en la provincia de Guayas (Ecuador)
}

\author{
Jaramillo, Rusbel a,b* - Medina, Klever a - Recalde, Alejandra a \\ Pastás, Katty a - Bedoya, Daniel a - Ramírez, Verónica ${ }^{\text {b }}$ \\ agencia Ecuatoriana de Aseguramiento de la Calidad del Agro, AGROCALIDAD, km 14 1/2 \\ Vía Interoceánica Granja del MAGAP, Tumbaco, Ecuador \\ bUniversidad de las Fuerzas Armadas - ESPE, Departamento de Ciencias de la Vida y Agricultura, Sangolqui, Ecuador
}

\section{RESUMEN}

El cadmio es un metal pesado que provoca serios daños a la salud humana. Su presencia natural o antropogénica en agua y suelo es motivo de preocupación debido, en gran medida, a la posibilidad de acumularse en alimentos, entre ellos el cacao, uno de los princi-pales productos de exportación ecuatorianos. Con el objetivo de encontrar la profundidad óptima de mues-treo para la determinación de concentraciones de cadmio y nutrientes en cultivos de zonas cacaoteras, se muestrearon y analizaron suelos de terrenos agríco-las de seis organizaciones que conforman la asocia-ción Unión de Organizaciones Campesinas Cacaoteras (UNOCACE), en la provincia de Guayas. Las características fisicoquímicas más relevantes de las muestras de suelo (a distintos rangos de profundi-dad) y su contenido de cadmio fueron determinadas. En total, se tomaron y analizaron 897 muestras com-puestas de suelo. Casi la totalidad de las muestras presentaron concentraciones de cadmio total por debajo de 0,4 ppm, cumpliendo con el criterio estable-cido por la legislación ambiental ecuatoriana $(0,5 \mathrm{ppm})$. Solo en una organización, ubicada en el cantón Naran-jal, se observó un valor promedio por encima de aquel criterio legal $(0,62 \mathrm{ppm})$. Se observó que las concentra-ciones más altas de cadmio estaban en las muestras en rango de profundidades más superficial $(0-20$ y 20-40 cm), lo que hace presumir que el metal se encuentra asociado a la materia orgánica. La infor-mación obtenida puede servir de base para futuros estudios, mismos que deberían además evaluar la biodisponibilidad del cadmio presente en el suelo.

Palabras clave: Biodisponibilidad, cadmio en suelos, Ecuador, metales pesados, producción de cacao.

* Correspondencia a: Agencia Ecuatoriana de Aseguramiento de la Calidad del Agro, AGROCALIDAD, km 141/2. Vía Interoceánica Granja del MAGAP, Tumbaco, Ecuador. Teléfono: 593 2372845. Correo electrónico: rusbel.jaramillo@agrocalidad.gob.ec 